\title{
Cardiac Kaposi Sarcoma
}

National Cancer Institute

\section{Source}

National Cancer Institute. Cardiac Kaposi Sarcoma. NCI Thesaurus. Code C5363.

A Kaposi sarcoma arising from the heart. 